\title{
School Children with Epilepsy: Their Voice, Our Concerns
}

\author{
Ravinder Singh ${ }^{1}$, Upmesh K.Talwar ${ }^{2}$. Vibha Sharma ${ }^{3}$, VKS Gautam ${ }^{4}$ \\ ${ }^{1}$ Department of Medical Anthropology, ${ }^{3}$ Clinical Psychology, Neurosurgery ${ }^{4}$ \\ Institute of Human Behaviour \& Allied Sciences, Dilshad garden, Delhi, India \\ ${ }^{2}$ Former Assistant Professor, Department of Social Work, CUHP, Dharmshala, HP
}

\begin{abstract}
Paper analyses five case studies of school children with epilepsy. Contents of the case studies reveal the Voice of the children and their concerns. Case studies focus on the problem of these children in school, as well as in the family, family and kinship care, and who cares for the epilepsy in family?
\end{abstract}

Keywords : School Children, Epilepsy, Family \& Kinship care.

\section{INTRODUCTION}

Normally caring is considered to be the work of the women followed by other kinsmen in the family. Can the family and kinship caring intervention be analyzed in home or in community or in hospital situation? Anthropology of caring has already explored a new path for individuality, alterity, gender relations, and new form of sociality in everyday life experiences of caregivers, spouses, children, and other relatives who provide day to day care to person with illnesses living in the home [1]. Anthropologists have reformulated the kinship as the study of form of caring and being cared for [2]. The family and kinship care is the complementary part of comprehensive patient care in the families of patients with dementia and epilepsy [3].

Epilepsy is a neurological disease of the cerebral malfunctioning characterized by a pattern of repeated, sudden brief attacks of altered consciousness, motor activity or sensory phenomena. Studies have been reported on the epilepsy covering the different aspects and about 10 million people are suffering from epilepsy in our country [4-5]. There is also some indication that some sub-groups have a genetic predisposition to lower seizure thresholds and consequently a much higher prevalence than is reported within their general populations [6]. This condition poses specific problems affecting their physiological, behavioral or cognitive consciousness in everyday life of these children. The psychosocial aspects of the epilepsy patients in Bareilly district [7], ethical and legal issues related to patients with dementia and epilepsy [8], childhood epilepsy and knowledge, attitude and perception of the school teachers of Delhi [9] have already been reported. Spiritual psychotherapy of caregivers while caring epilepsy patients, particularly among children [10] and care giver burden, personality characteristics and coping strategies of care givers of patients with epilepsy [11] have been reported . A well known psychiatrist and medical anthropologist, Arthur Kleinman, has very nicely documented all these aspects as the social course of epilepsy suffering, chronic illness as social experiences in his field work in China, India and American ethnic groups [12]. Many people, including children, are neurologically fit but still they face the psychological and social consequences of the epilepsy [13]. Here in this paper we have illuminated the voice of the school children with epilepsy, family based kinship care, their importance and issues of care giver.

\section{Material and Methods}

Interview of 38 Epilepsy patients' and their care givers were conducted between August 2006 and July 2007. A semi-structured schedule was used for interview during their neurology OPD visit as well as through home visits to substantiate the desired information at the week end. Initially one of us (RS) visited some of them to complete the information. Such information which they could not share, about traditional healing practices, if they consulted, were discussed and finally noted? Most of them do not like to share with the physicians in their consultation rooms who, as they believe, exclusively meant for diagnosis, prescription and do not like to listen these aspects of alternative healing consultations. Five Case Studies of school children with epilepsy were selected out of the 38 and reported.

\section{School Children with Epilepsy: Five case studies}

We are giving a brief case studies revealing their voice, family and Kinship based care, narrative of their suffering in school (pseudo name are given)

1. VK, 16 years, studying in 12th class and preparing for board examination. His mother narrates about his seizure began, when he was eight years old. Toady nearly eight years passed in the treatment for the seizure. During past eight years, some traditional healers treated him for one year in his maternal uncle 
house in Himachal Pradesh. These healers used, as his mother narrates further, tabeej, mantra rituals and sacred thread, etc. but VK had no cure in his maternal uncle house. He visited the different places for the traditional treatment including the well known big hospital in Delhi. Initially, as his mother tells that she did not knew it is a disease, while one doctor treating him then told her that it is a disease, epilepsy, and doctor referred him to this hospital and VK re-assumed the treatment in the tertiary care neuropsychiatric center. Further she adds about VK that he feels shy and hesitates visiting the hospital after an interval of fifteen days. His mother admits the trouble in bringing him here in outpatient department for the routine checkup. He does not want to come very frequently, she continues, further that his friends and neighbor make fun of him by saying that his treatment is going on from this hospital, and often feels it. As his mother says

\begin{abstract}
"Main usko chupake lati hun taki padosi bhi nahi jante ke eska ellaz yahan se ho raha he aur VK ko ye achha nahi lagta ki usko bar bar yaha ana padta he!" (I bring him hospital in the hiding ways, he does not like to visit the hospital frequently, even his friends and our neighbor do not know about this treatment. It is only we the family know the about it and we do not share his treatment with other).
\end{abstract}

However his treatment continues from the hospital. His seizures are now under control.

2. KV, 13 years boy, studies in primary class in his home town Moradabad, having the complaints of seizures since 2007. He had nine episodes of seizures on 27 May 2007 and followed by 3 seizures on the next day. Because of the complaints neither he was allowed to appear in the examination nor he appeared and finally he dropped a year in the fifth class. KV stays with his uncle in Moradabad and his father, work in Gajrola as Patwari, visits him on weekend and could not pay attention to his academic activity. In the class his classmates tease him due to his Caste and often pass the derogatory remarks due to his caste. It creates tension and haunts him. He requested his father to change school due to this class atmosphere. KV feels disturbed in home could not concentrate on the studies. Further common shouting or asking in harsh words to get thing done caused ultimately seizures (?). This patient was referred on the advice of the some relative to this hospital.

3. SNZ, 12 years Muslim poor girl from Tahirpur near our hospital, she has been diagnosed for the seizure for the five years. She had first episode of the seizure at the age of seven years in the school and then it continues for next few days. Her parents took her to the local healer of their community, Molvie, on first episode of the seizure and for the 6 months she remains under this treatment. But her parents visited again another healer, Ojha but nothing cured her illness. Her father visited in the hopeless situation to Pediatrician, who advised her father for the proper neurological treatment and referred to our hospital. She had reduced frequency of seizure after the treatment, it reduced from every day to week, then in ten days to once in a month within a year and her seizures were under the control. Her school teacher advised her not to attend school and parents though continued her studies. She lost the precious years of school education due to this disease.

4. SND, 18 years male, a 9th class student of Aligrah has been suffering the seizure disorders for the past three years and discontinued his studies because of seizure. He used to go to school on cycle $6 \mathrm{~km}$ one way . He had first episode of seizure at the age of 15 years and his family members took the treatment form the local healers in Chachera, Aligrah, UP. He also went to Vaid Rajvir Singh who is also well known as Bhagatji who had claimed the cure of several such cases of the epilepsy. SND was given the treatment for one year and the vaid treatment gave no relief to him. Though the cost of herbal medicinal treatment was Rs. 42/- per month. While he was being examined for the diagnosis in the OPD then his father already had planned for another visit to Anupshare near Blundshar for other traditional healer. But a neighbor, who had been taking the treatment from the hospital, suggested his father to visit this hospital for the treatment. His treatment continues now from the hospital but still his family members are looking for the alternative healing. SND wants to continue his studies but his parents prevented him due to fear and social stigma felt in school as well as in neighborhood areas of his house. It seems that family feel the stigma in the society.

5. USH, 16 years girl from Nand Nagari, Delhi, student of $8^{\text {th }}$ class had complain of seizures for four years. She continued the treatment from our hospital. Her seizures subsequently controlled. Seldom episode of mild seizure disturb her and may occur in the school. Here she expresses that their teachers and class mates help at the time of the seizures. She felt that both teachers and other students are helping her at the time of need. She suffers despite the controlled seizures and she says

"Kash mai mar jaun, bahut ho gaya es bimari se, har samay dar laga rahta he" (If I could die, it is enough of seizures. Every time I am afraid of seizures!)

She further expressed expenditure strains on this disease made her more sick as she adds 
"bahut paise kharch ho gaye, lekin kuch tik nahin hota, acha hota ki mai mar jaun! Na tik se pad sakete he, Na khel sakete he!" (Much has been spent on this disease; nothing turns right to my disease. It would be better if I die. Neither I cannot study well nor can play well)

Ush has developed a guilt which is giving her more suffering than disease.

\section{Their voice, our concerns}

Let us see in above case studies: how do school children with epilepsy voice their concern with disease, its entire course of treatment, care in the family and challenges in the school.

The analysis of the case studies of school children reveal that most of them first encounter the local healer in locality, continue the treatment for some time, Muslim and Hindus parents prefer to visit their respective healers: Muslim to Molvie and Hindus to Ojha, bhagat, spend much time in such healing adds to the severity of the diseases and all the children in school as well as in community experienced stigma. In most of the cases children elaborately described their experiences and the manifestations of the epilepsy. They feel as the epilepsy is disease of uncertainty and disappointment. One of the Children said that he always believed the most recent seizure to be the last and he experienced an enormous disappointment and sadness after each new seizure. Medical treatment makes these children more curious about the medicine how long these will continue. There were expressions of a negative self-image and even of self-destructive tendencies, as we had seen in case of Ush. There is similar expression in many other cases. The feeling of insecurity was however often present. Almost all children had experienced a negative attitude.

They experienced harassment at school because of epilepsy, and had a strong negative impact on their lives. When discussing their leisure time activities, the attitudes of others often emerged as main problem.

Cognitive problems were commonly reported. As in case of $K V$, a school boy who not only suffered from the seizures disorders but also facing the caste discrimination in the class from the classmate as well as from the teachers and forced to discontinue his studies, where as in case of SNZ, 12years, a Muslim girl from lower socio economic group also faced the social discrimination in the class due to disease. School going children with epilepsy mostly complain concerned to their memory, but a few experienced speech difficulties or attention difficulties, feelings of fatigue or being easily exhausted were also frequently reported.

Family and kinship care of school children with epilepsy indicates that most they are cared by their parents, besides maternal and paternal uncle, as in case of $V K$ and $K V$. However, school going girls remains under the supervision of mothers and frequently visits hospital for the treatment. Their parents take decision about their children, boys or girls, where to go for the treatment and parents are around them rarely other kinsmen care them for long. Perhaps it is due to the stigma associated to the disease. In sum, school children are entirely depend upon the parents who are occasionally supported by close relatives.

\section{CONCLUSION}

We feel there should be a wide awareness about epilepsy among the school teachers as well as among students of the school. Besides, there should be a regular training or orientation to such people- people with epilepsy, under care giving model, particularly, for the school children with epilepsy. It may comprised of informative materials about the epilepsy, associated myths, do's and do not, in case of epileptic of attack in home situation as well as in school situation, etc all should be coupled with regular training to the family members caring the epileptic children. Similarly school teachers should be sensitized about their plight and special care in time of the Seizure. In many developing countries, people with epilepsy are still thinking it as the madness and consult often the traditional healers, as we had seen in our cases studies. A simple model for the management, school children with epilepsy, must be based on existing school-based health care providers, trained staff to provide such services in need and making referral to nearby tertiary care facility centre, can reduce the burden of the caregivers in the family as well as in school[5].

\section{Acknowledgements}

We are thankful to Dr Meena Gupta, former Director, IHBAS and Professor of Neurology in GB Pant hospital Delhi for her encouragement.

\section{REFERENCES}

[1] Saillant, Francine and Serge Genset (2007). Medical Anthropology-Regional Perspective and shared Concerns, ed. Blackwell Publishing,USA.

[2] Borneman, John(1997). "Caring and Being Cared for: Displacing the Marriage, Kinship, Gender and Sexuality." International Social Sciences Journal, 154:573-584 
[3] Singh, Ravinder; Vibha Sharma and Upmesh Kumar Talwar (2013). Patients with Epilepsy and Dementia: Does Family and Kinship Care Matter? Advances in Anthropology, 2013(in press)

[4] Gourie-Devi,M, G.Gururaj, P Satishchandra and D K Subbhakrishna(2004a).Prevalence of Neurological Disorders in Bangalore, India: A Community- Based Study witrh a comparison between Urban and rural Area. Neuroepidemiology 2004; 23:261-268

[5] Gourie-Devi,M, G.Gururaj and P Satishchandra (2004b). Delivery of Epilepsy Care to the Community: Towards the national Epilepsy control Programme. In Mental Health-An Indian perspective(1946-2003)Edited by S P Aggarwal, DGHS, Ministry of H \& FW, New Delhi.

[6] Chandra,V., R. Pandav, R. Laxminarayan,C.Tanner, B.Manyam, S. Rajkumar, D. Silberberg, C. Brayne, J.Chow, S.Herman,F. Hourihan, S. Kasner, L. Morillo, A. Ogunniyi, W.Theodore, and Z. Zhang( 2006). Neurological Disorders. Chapter-32 in Mental health Disorders. The International Bank for Reconstruction and Development / The World Bank, 2006

[7] Rani, Ajita and Ravinder Singh (2012). People Living with Epilepsy: Exploring psychosocial aspects of the Epilepsy patients in Bareilly. Abstract. Proceeding of Argentinean Congress on Neuropsychiatry and Cognitive Neuroscience. 29-31 August, 2012, Buenos Aires - Argentina.

[8] Sharma, Vibha; Ravinder Singh, Upmesh K Talwar and Mahesh Bhargava (2011). Ethical and Legal Issues related to Dementia and Epilepsy, Chapter-25 in Clinical Neuropsychology Assessment and Rehabilitation: A Practical Approach, ed. Vibha Sharma and Shazadi Malhotra. Published by Harprasad Institute of Behavioral Sciences, Agra, UP.

[9] Khurana, Sarbjeet; Kiran Bala, Ravinder Singh and Vibha Shrama(2012). Childhood Epilepsy: Knowledge, Attitude and perception of the School teachers of Delhi. Abstract. Proceeding of $56^{\text {th }}$ Annual Conference of Indian Public Health Association(IPHA) for Public Health Priorities for the 12 $2^{\text {th }}$ Plan. 10-12 Feb, 2012, Kochi. Abst No. 486, Page 28.

[10] Singh, Nidhi; Vibha Sharma and Ravinder Singh (2012a). Spiritual psychotherapy of Caregivers of patients with epilepsy: An Indian perspective for Care givers. Abstract. Proceeding of International Conference on Recent Advances in Cognition and Health, January, 23-24, 2012, pp 40-41, Organised by Deptt. of Psychology, SAP(DRS1), BHU, Varansai, India

[11] Singh, Nidhi; Vibha Sharma and Ravinder Singh (2012b). Care Giver burden, personality characteristics and Coping strategies of Care givers of patients with epilepsy. Abstract. Proceeding of International Conference on Recent Advances in Cognition and Health, January, 23-24, 2012.pp 40-41 Organised by Deptt. of psychology, SAP(DRS1), BHU, Varansai, India

[12] Kleinman, Arthur (1995). The Social Course of Epilepsy: Chronic Illness as Social Experience in Interior China, Chapter-7, in Writing at the Margin-Discourse between Anthropology and Medicine. Published by University of California Press, USA.

[13] Singh, Ravinder, Kiran Bala, R K Jha and U K Talwar (2009). People Living with Epilepsy-Narratives of OPD patients. Unpublished paper submitted to Panel on Public Health and Anthropology, 16th World Congress of The International Union of Anthropological and Ethnological Sciences (IUAES 2008) $27^{\text {th }}$ to $31^{\text {st }}$ July 2009 in Kunming, Yunnan, China. 